\title{
Microsystems for Biomechanical Measurements
}

\author{
JAMES J. NORMAN, VIKRAM MUKUNDAN, DANIEL BERNSTEIN, AND BETH L. PRUITT \\ Department of Mechanical Engineering [J.J.N., V.M., B.L.P.], and Department of Pediatrics [J.J.N., D.B.], \\ Stanford University, Stanford, California 94305
}

\begin{abstract}
The use of microtechnology to make biomechanical measurements allows for the study of cellular and subcellular scale mechanical forces. Forces generated by cells are in the few nanoNewton to several microNewton range and can change spatially over subcellular size scales. Transducing forces at such small size and force scales is a challenging task. Methods of microfabrication developed in the integrated circuit industry have allowed researchers to build platforms with cellular and subcellular scale parts with which individual cells can interact. These parts act as transducers of stresses and forces generated by the cell during migration or in the maintenance of physical equilibrium. Due to the size and sensitivity of such devices, quantitative studies of single cell and even single molecule biomechanics have become possible. In this review we focus on two classes of cellular force transducers: silicon-based devices and softpolymer platforms. We concentrate on the biomechanical discoveries made with these devices and less so on the engineering behind their development because this is covered in great detail elsewhere.

(Pediatr Res 63: 576-583, 2008)
\end{abstract}

$\mathrm{C}^{\mathrm{e}}$ ll-generated forces play an important role in many physiologic processes, and measurements of single cell mechanics are necessary to understand these functions. Microscale systems for force and displacement sensing provide appropriately scaled metrologies for assaying single cells. This review seeks to highlight several opportunities and solutions for single cell measurements and their impact on biology and medicine.

Cells can both generate and sense forces in the extra cellular matrix (ECM) and basement membranes that comprise their three-dimensional in vivo environment. These forces can be transmitted through the ECM proteins or through direct cellto-cell contact and sensed by neighboring cells. These forces are widely recognized to influence cellular level processes that regulate both normal and pathologic states (1-3). Forces present in the cellular environment play an important role in events such as wound healing, tissue morphogenesis, and regeneration. Tissue morphogenesis is a complex process involving both spatial and temporal interplays of biochemical factors and mechanical tensions. Tensions present during embryonic development can influence proper growth and organization (4-8). Tension generation and mechanical force transmission by cells due to migration, stress fiber formation, or active cross-bridging (as in sarcomeres) are of particular interest in diseases having pathologic formation of structural

Received: December 13, 2007, Accepted: January 25, 2008

Correspondence: James J. Norman, PhD, Department of Mechanical Engineering, Stanford University, 496 Lomita Mall MC 4040, Stanford, CA 94305-4040; e-mail: jjnorman@stanford.edu proteins within cells. For example, changes in sarcomeric density, structure, and organization in dilated and hypertrophic cardiomyopathy play a critical role in the contractile properties of cardiac myocytes (CMs) (9-13). Recent discoveries of large mechanical property changes in red blood cells because of malarial infection have shed light on the molecular pathways involved in the cellular level pathology (14). Fibroblasts migrate into wound areas, and the tension generated by the cells closes the wound and reorganizes the matrix to form scar tissue $(15,16)$. The tension generated in the ECM also acts as a feedback mechanism to regulate fibroblast function $(15,17,18)$. Similarly, studies of the mechanical properties of epithelial cancer cells have raised questions about the role of cell mechanics in cell mobility and metastasis (14). The magnitude and localization of generated forces and how they correlate to cytoskeletal proteins such as actomyosin filaments and the various focal adhesion proteins can provide insight into cellular level pathogenesis. Understanding how the forces are generated, sensed, and transmitted by the subcellular machinery is an important piece of the cell biology puzzle that could help elucidate what goes wrong when tissues fail to form or heal properly.

Studies on tissue mechanics began with the use of traditional materials testing platforms such as tensile stress apparatuses (19-21). These devices, however, only provide a macroscale study of the tissue and do not allow isolation of the cellular components from the structural components of a tissue, such as the ECM proteins, nor do they allow for direct measurement of single cells. Single-cell platforms were first developed by scaling two-point tensile-testing methodologies. For example, one of the most common methods for studying myocyte mechanics employs drawn-glass pipettes with a cell glued between the ends. Cell contraction forces are then inferred from the deflection and stress in the pipettes. This method is very time consuming and allows for study of a single cell in each test (22-24). Where single-cell, highthroughput platforms for studying cell mechanics are required, devices leveraging Integrated Circuit (IC) industry fabrication methods have been pursued. ${ }^{1}$

Microelectromechanical Systems (MEMS) grew out of IC fabrication for the integration of microscale mechanical fea-

Abbreviations: bioMEMS, biological microelectrical mechanical systems; CM, cardiomyocyte; ECM, extracellular matrix; IC, integrated circuit; MEMS, microelectrical mechanical systems; mPADs, microfaricated post array detectors; TFM, traction force microscopy; PDMS, poly(dimethyl siloxane) 
tures and transducers with electrical components on a single device. Several resources have detailed the fabrication methods and basic MEMS device fundamentals (25-29). Using this MEMS toolbox, engineers and biologists have worked together to create several interesting platforms with surface features and force ranges at the scale of single cells (0.1-100 $\mu \mathrm{m}$ and nanoNewtons to microNewtons) $(30-32)$. These platforms allow for controlled cell environments where the spatial arrangement of each cell can be defined through the surface topography. This has lead to over two decades of research on how feature size, geometry, and mechanical properties influence cell growth, apoptosis, organization, migration, and differentiation. A great advantage to cell biologists, microsystems can be created at such small scales, and the batch fabrication methods allow for hundreds or thousands of parallel devices on a single platform the size of a standard Petri dish. Such arrays allow data acquisition from each individual cell in an entire population and result in statistically powerful studies.

There are two main classes of microplatforms used for studying the mechanics of cells, silicon-based and polymerbased microsystems. Silicon-based devices created using standard IC methods are designed to contain both moving parts and electrical sensors for observing and recording generated forces. The mechanical parts and the circuitry are matched to the size of a single cell and allow parallel studies of individual cells in a population. These devices are limited in their array size because of the need for electrical interconnects. They also typically require access to a sophisticated fabrication facility with a variety of processes being required such as lithography, plasma etching, and wire bonding. These systems typically lack optical transparency and have limited biocompatibility. However, new materials and surface functionalization can overcome these issues and makes silicon an active area of research for biological studies.

Soft lithography (lithographic fabrication of devices directly in polymers by pattern transfer of silicon) has lead to a new class of force transducers (33). The use of soft polymers such as the epoxy-based resist SU-8, polyacrylamide, poly(dimethyl siloxane) (PDMS), and biological gels such as Matrigel have begun to replace electromechanical devices. Although soft polymer devices are not as amenable to moving parts and integrated electrical circuitry, they are simple to fabricate even in biology labs that may have no MEMS experience. Initial lithographic patterning of silicon wafers to create a master pattern is all that is typically needed. The elasticity of polymers is a better match to cell properties than brittle and stiff silicon. The optical clarity of polymers ( $v s$. opaque silicon) is a property desired by biology researchers who want to correlate cell behavior on the surface with molecular biological processes. Polymer surface chemistry is also readily modified for biocompatibility. In polymer force sensing devices, optically measured displacements of beams (or fluorescent beads in a compliant substrate) are used to infer the forces generated by cells. The small-scale (tens of nanometers) achieved using current fabrication and observation techniques allows for spatial correlation of cell generated forces with cytoskeletal features, focal adhesions, and surface proteins. This subcellular spatial resolution is not readily available with silicon-based force transducers.

In this review, we discuss several microsystem platforms that have been used to study force production and sensing in a variety of cell types. These devices have been divided into categories according to their suitability and application to various biological function related to mechanics, namely traction forces and migration, biochemical pathways, focal adhesion measurements, contraction forces, and stiffness and cytoskeleton. Finally, we discuss a new trend in studying cell mechanics involving embedded sensors and actuators for applying controlled forces to cells. These devices provide new insight to how cells actively respond to the forces they are subject to. This review concentrates on the biological discoveries that have been made, however, given the wide topical area and the limited space, is not comprehensive. For more detail of the analytical and computational methods used, readers are referred to the original articles.

\section{CELL TRACTION AND MIGRATION FORCES}

When a cell migrates across a surface, it applies traction forces to that surface. Cell generated traction forces were first investigated by Harris et al. using thin silicone-rubber sheets (34). This method examined wrinkles created on a rubber surface by migrating fibroblasts. Galbraith and Sheetz first used microfabricated silicon cantilever beams to measure traction forces exerted by motile cells like fibroblasts and understand the dynamic force transfer at focal adhesions (Fig. 1) $(35,36)$. The measurements were made with an array of polysilicon cantilevers with pads on the end. The traction forces exerted by the migrating cells as they passed over the pads were inferred from beam deflections which were observed optically. The force resolution was limited by the optical measurement to around $5 \mathrm{nN}$ for a beam stiffness of 75 $\mathrm{nN} / \mathrm{mm}$. Observations of fibroblast migration showed forces changed from backward to forward direction between the lamella and the tail of the cell with maximum forces at the tail $(+100 \mathrm{nN})$ an order of magnitude greater than those in the lamellar regions $(-5 \mathrm{nN})$. Immunofluorescence imaging of $\beta 1$-integrin suggested forces were generated at a small number of focal adhesions. As one of the earliest applications of MEMS in cell biology, this experiment highlighted some of the key features of force generation in migrating fibroblasts. This technique was limited to force measurement in only one direction with spatial resolution equivalent to beam spacing and bandwidth limited by the required postprocessing of video data.

The directional and spatial resolution limitations of this technique were overcome by Traction Force Microscopy (TFM) by the incorporation of fluorescent beads into polyacrylamide gel substrates, allowing easy visualization of the deformations created in an elastic substrate through traction forces generated by cells (37) (Fig. 2). Improvements made through the use of time-lapse video-microscopy and improved computational algorithms for determining the deformation field and shear of the substrate opened the way to quantitative measurements of traction forces generated while cells migrate 

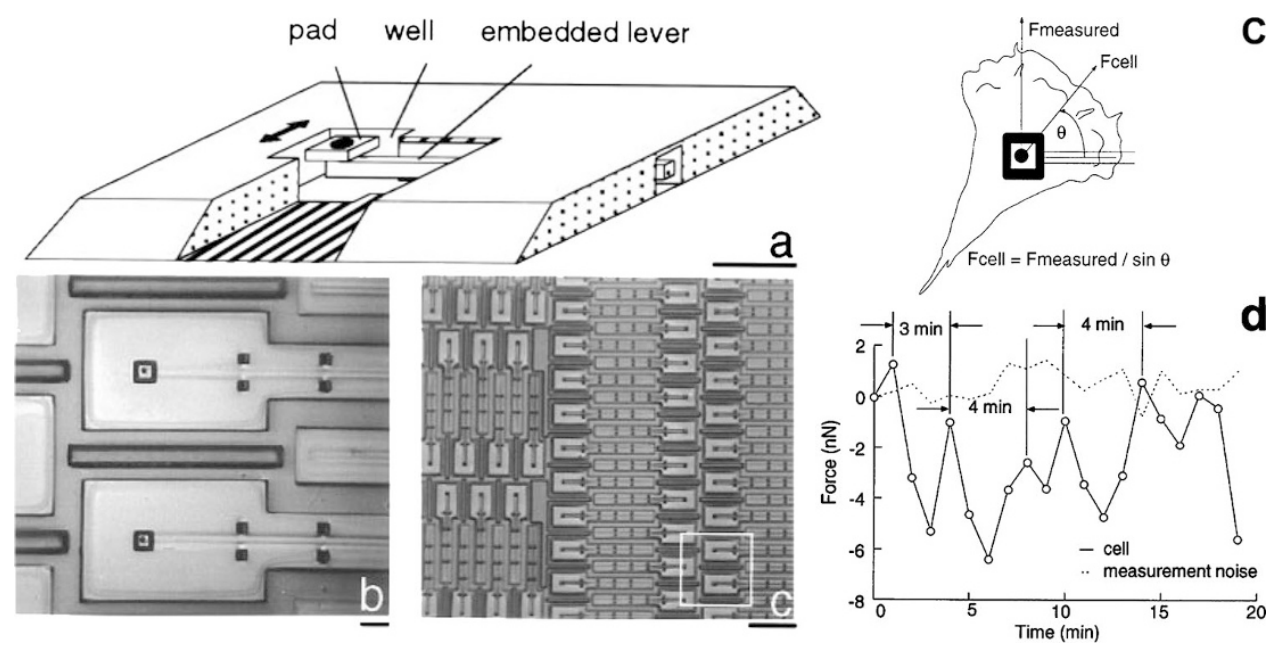

Figure 1. $(A-C)$. Schematic and images of micromachined array of pads for cell traction force measurement. The migrating cells attach to the pad and the traction forces deflect the embedded lever. The force is inferred from the deflection. $D$. Schematic of cellular interaction with the pad indicating the direction of the force. Only the forces normal to the direction of the cantilever are measured in this technique. E. A plot of measured forces indicating fluctuations and measurement noise. Images reprinted from Galbraith CG and Sheetz MP, Proc Natl Acad Sci USA 94:9114-9118, Copyright @ 1997 National Academy of Sciences, U.S.A., with permission.
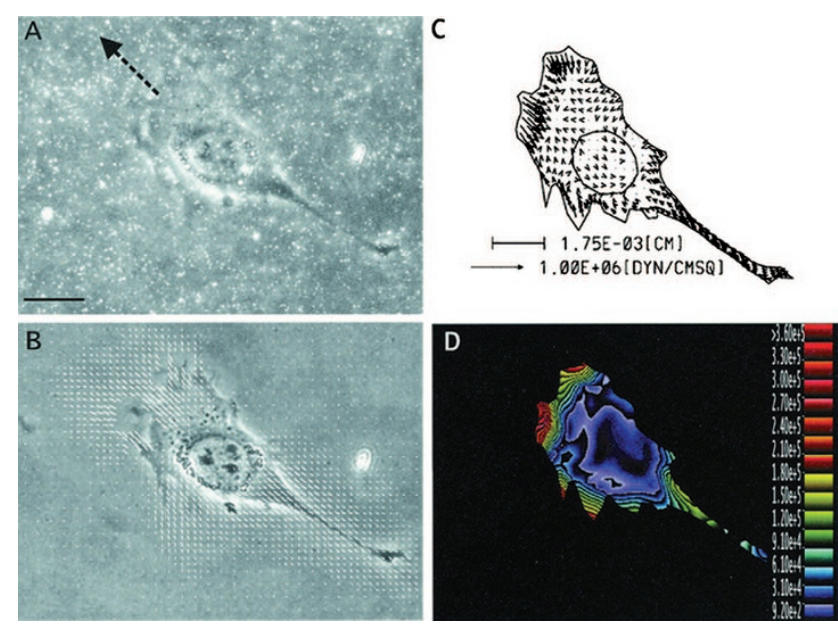

Figure 2. (A). Fluorescent beads embedded in polyacrylamide gel with attached migrating fibroblast (arrow shows direction of migration). (B). Deformation vectors of the substrate. $(C)$. Vector field of traction stresses generated by the cell. $(D)$. Color map showing local magnitude of traction stresses. Image reprinted from Munevar S, et al., Biophys J 80:1744-1757, Copyright (C) 2001 The Biophysical Society, with permission.

over a surface (38). Surface-attached cells created tension in the polyacrylamide substrate causing deformations that moved the beads from their reference position. This technique involved imaging cells after they have attached and then removing the cells via trypsinization to relax the substrate and get the reference position of the beads. The actual determination of force maps is challenging and requires the use of computationally intensive algorithms for determining the applied forces. TFM has a reported spatial resolution of approximately 4 to $6 \mu \mathrm{m}(39-41)$. Besides polyacrylamide gel, this technique has also been used with gelatin and PDMS substrates (41-43). For a more detailed theory behind the computation of traction forces using fluorescent bead substrates, readers are referred to the review by Wang and Lin (44).

A strength of TFM is the ability to map traction forces over the basal surface of a cell. In mapping traction forces in locomoting fibroblasts, Pelham and Wang observed the greatest forces were found at the front of the migrating cell (39). This finding was contradictory to the behavior in locomotion studies using micromachined silicon cantilevers reported by Galbraith and Sheetz who observed greater traction forces concentrated at the rear of a cell (35). However, different fibroblast types were used in each study and the device by Galbraith and Sheetz had limited directional detection capability, both of which could have contributed to the observed difference.

\section{BIOCHEMICAL PATHWAYS}

TFM has been extended to study the effects of various biomolecules and environmental conditions on traction forces: $\alpha$-smooth muscle actin in myofibrils (45), blebbistatin, a myosin II inhibitor, on migrating fibroblasts (46), $\alpha 6 \beta 4$ integrin in carcinoma cells $(47,48)$, phosphorylation of the heat shock protein, HSP27 on the actin cytoskeleton (49), role of electric fields in cellular repositioning (50), and effect of substrate compliance (51). Gaudet et al. showed the influence of collagen concentration on fibroblast migration and found that force generation was dependant on cell area; they estimated the tension in an integrin-collagen bond at $\sim 100 \mathrm{pN}$ (52). Using the mapping ability of TFM, Munevar et al. found the front and rear cell-substrate adhesions play different roles during migration; frontal adhesions provide the major force transmission sites whereas rear adhesions play a passive role in anchoring the cell (53). They also observed that 3T3 fibroblasts transfected with the oncogene H-ras had abnormal migratory behavior - including poor directional stability, transient adhesions and increased migratory velocity - behavior associated with metastasis (38).

\section{FOCAL ADHESION FORCES}

Two variations of TFM were introduced by Balaban et al. (54). These methods used continuous PDMS sheets, created 
using soft lithography, to mold the base platform. Instead of randomly distributed fluorescent markers in the bulk of the substrate, the patterns were created on the surface in a precise row-column arrangement. The first method involved creating a regularly arrayed pattern of pits in the surface of PDMS. In the second method, the pattern, also in a regular array, was created using fluorescent photoresist dots embedded in the surface of the PDMS. This had the advantage over traditional TFM in that deformation through application of force was easily monitored, because the markers were placed in a regular array. Any deviation of a marker from this regular array indicated an application of force. The fluorescent marker method has the advantage that the markers are much easier to see under large cells than the pits in the PDMS. Using these platforms, average force for a single fibroblast focal adhesion was found to be $10 \mathrm{nN}$. There was a positive correlation between force and focal adhesion area; however, the stress at a single focal adhesion was constant at $5.5 \mathrm{nN} / \mu \mathrm{m}^{2}$. From this, they estimated the force per integrin molecule at $1 \mathrm{pN}$.

Tan et al. introduced Microfabricated Post Array Detectors (mPADs) as an alternative method to TFM (55). mPADs are PDMS arrays of microposts that have the appearance of a "bed of nails" and act as cantilevers (Fig. 3 A). Cells lie on top of the bed of microposts and once attached, forces generated through stress-fiber formation or contraction will cause deflections of the posts. The posts are created using softlithography techniques and provide discrete areas of attachments (i.e., the posts) for the cells. Each of these discrete attachments can be analyzed in isolation from the rest of the substrate, unlike TFM which needs intensive computational algorithms to localize the forces in the continuous substratum to the position of the markers. From beam theory, the deflection of the tip of the micropost has a simple linear relationship to the applied force (Fig. $3 \mathrm{~B}$ ). The goal is to obtain extremely sensitive microposts (i.e., low-spring constant) such that large displacements are observed from applied forces. The discrete nature of the microposts decouples the generated forces at the point of attachment from the rest of the substrate thereby limiting influence from neighboring cells or posts. Spatial correlation of proteins and microposts can be achieved through immunohistochemical staining. These studies determine which proteins are implicated in force production, how their expression level changes with levels of force production, and how their arrangement influences direction of the forces (Fig. 3 C) (56).

Mechanical characterization of mPADs and how cells interact with the microposts has benefited from the use of finite element analysis. Proper micropost spacing to avoid sagging of cells into the interpost space can be designed (57). Accuracy of the linear model has been tested for various geometries, aspect ratios, and displacement ranges of microposts $(57,58)$. Of course, variations from the ideal columnar geometry due to fabrication tolerances can greatly influence the sensitivity of the micropost. mPADs have been used to study forces generated by motile cells such as fibroblasts, smoothmuscle cells, and epithelial cells (55,59-61). Beyond traction force measurements, the discrete nature of the microposts has been invaluable in understanding the role of various proteins in force generation. The role of cadherins, cell-cell junction proteins, has been studied by immobilizing an $N$-cadherin chimera to the top of microposts (62). Attachment to the microposts through cell-presented cadherins mimics cell-cell contacts. Observed deflection of the posts demonstrated that forces are transmitted through cadherins. Force transmitted through a single cadherin molecule was estimated at $10 \mathrm{pN}$. The role of cell-cell contacts was also studied in Madin-Darby canine kidney epithelial cells. Interestingly, larger forces were observed in Madin-Darby canine kidney epithelial sheets than in isolated cells suggesting mechanical cooperation between contacting cells (60). When the mechanical properties of the substrate are a determining factor in quantifying cell forces, the stiffness of the sensor may be altering the natural mechanical activity of the cell (63). Focal adhesions on more compliant microposts are less stable and less defined than those on more rigid ones; stiffer microposts also elicit greater forces in epithelial cells (61). Forces were found to be linearly proportional to total adhesion area when focal adhesions were greater than $1 \mu \mathrm{m}^{2}$, but forces were much greater when focal adhesions were smaller (55).

\section{CELLULAR CONTRACTION FORCES}

mPADs have found application in studying contractile forces of CMs $(64,65)$. Forces were found to be largest parallel to the long-axis of the cell. Application of isoproterenol caused myocytes to increase their force of contraction,
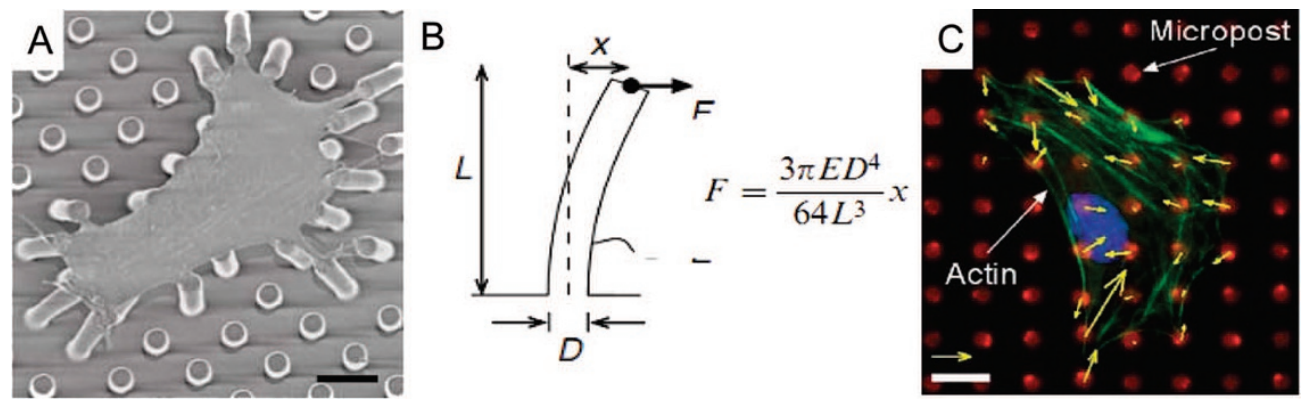

Figure 3. (A) smooth muscle cell attached to a field of microposts. Tension in the cell bends the posts. (B). Cell stained for visualization of actin (green) and nucleus (blue). Actin bundles are seen to terminate on the tops of the microposts $($ red $)$. $(C)$. Linear relationship between micropost bending and applied force where $D$ is post diameter, $L$ is length, $E$ is the material's Young's modulus, $X$ is the displacement, and $F$ is the applied force. Images reprinted from Sniadecki $\mathrm{NJ}$ and Chen CS, Methods Cell Biol 83:313-328, Copyright @ 2007 Elsevier Inc., with permission. 


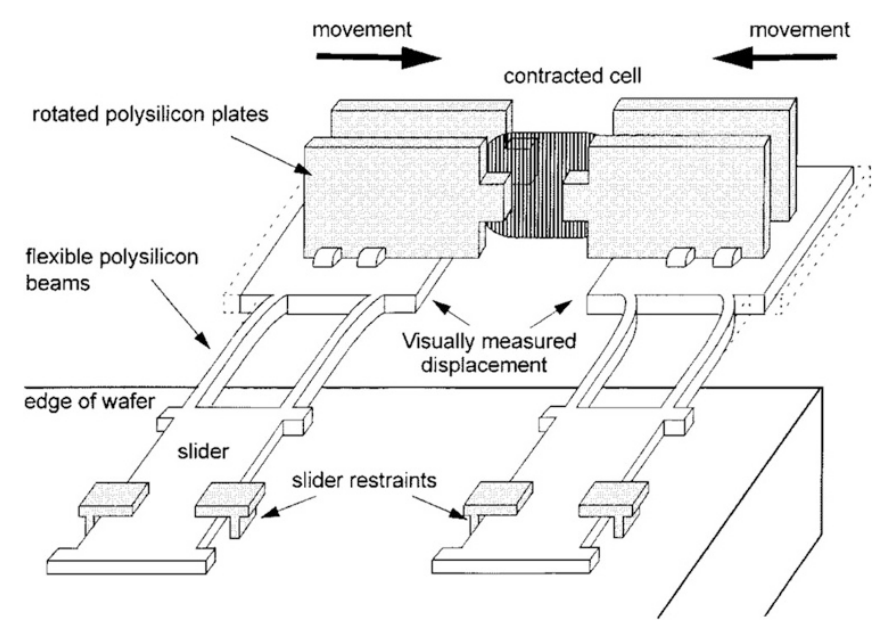

Figure 4. Schematic of 3D polysilicon force transducer for measuring contraction of heart cell. The cell is held between the rotated plates and the contraction force is measured by the deflection of the calibration flexible beams. Images reprinted from Lin G, et al., IEEE ASME J Microelectromech Syst 9:9-17, Copyright (C 2000 Elsevier Inc., with permission.

resulting in greater displacement of the microposts, thereby demonstrating mPADs use in observation of pharmacologically altered cell function (66). Sarcomeric structure in CMs is intimately related to force production; however, this structure is rapidly lost during in vitro culture (67). Microchannels and large anchoring posts were first shown to maintain neonatal CM morphology and sarcomeric structure by Motlagh et al. (68). Zhao et al. then incorporated these features into mPADs to maintain proper morphology and sarcomeric structure in isolated neonatal CMs $(64,68)$.

A 3D polysilicon based MEMS force sensor for measuring contractile forces in cardiac cells was developed by Lin et al. (Fig. 4) (69,70). The 3D structures were manually assembled with micromanipulators after surface micromachining processes (71). Cardiac cells were glued to the grips attached to cantilever force sensors and contractile forces were inferred from optically observed deflections of the calibrated polysilicon beam structures. The force sensors were miniaturized to a volume less than $1 \mathrm{~mm}^{3}$ and fit into fluidic chambers perfusing biological media. The contractile force of rat heart cells in the presence of $\mathrm{CaCl}_{2}$ activating solution was $12 \mu \mathrm{N}$ as measured with devices having spring constants around $0.57 \mathrm{~N} / \mathrm{m}$. This technique was used in a range of $\mathrm{Ca}^{2+}$ concentrations and the measured forces were fit to a Hill curve. These first MEMSbased measurements of cardiac cells agreed well with pipette- based measurements which often are problematic due to lack of substrate adhesions, cell handling damage, and uncontrolled length variation during contraction (72).

Cantilevers, as described above, are traditionally made from silicon-based material. Bending of the cantilever may be measured optically by image processing or via a reflected laser spot. Polymer-based cantilevers, however, offer platforms that have a compliance more closely matched to cells, are optically transparent, and are suited for studying actively contracting cells such as cardiomyocytes. Cardiomyocytes attached to the surface of a PDMS cantilever produce bending upon contraction that can be optically measured and quantified (Fig. 5) (73). This method allows for cooperative studies of selforganized CMs on cantilevers with large surface areas able to accommodate multiple cells. Using this system, both in-plane and out-of-plane bending of the cantilever can be monitored. Determination of the forces that result in such deformations have to be determined through extensive image processing and analytical computation or finite element modeling of the cantilever $(73,74)$. To obtain better control of cellular placement and organization on the cantilevers, microgrooves were created on the surface to orient cells lengthwise along the cantilever (Fig. 5 C) (75). These grooves allowed for cells to organize along the long axis of the cantilever so that the majority of generated force went into bending the cantilever along its length. Using flat cantilevers, forces generated by single cardiomyocytes were estimated to be 2 to $5 \mathrm{nN} / \mu \mathrm{m}^{2}$. This increased to 4 to $7 \mathrm{nN} / \mu \mathrm{m}^{2}$ on grooved substrates, suggesting an important substrate interaction effect (75).

\section{CELL STIFFNESS AND CYTOSKELETON}

Saif and coworkers developed a silicon cantilever-based system for studying the mechanics of single cells under large deformation $(76,77)$. This technique was specifically developed to address some of the drawbacks of other methods in measuring stiffness of cells. The force transducers were functionalized with fibronectin to promote adhesion to cells. The external stage was moved to stretch the cell and the deflection of the cantilever tip with respect to the stage was optically observed (Fig. 6). The cell force-deformation curves thus obtained were described by a truss model of cytoskeletal stiffness, with microtubule compression struts and actin tensile fibers (76). The cell deformations were linear and repeatable for large deformations, though linearity and reversibility were lost in the presence of cytochalasin-D, an actin polymerization
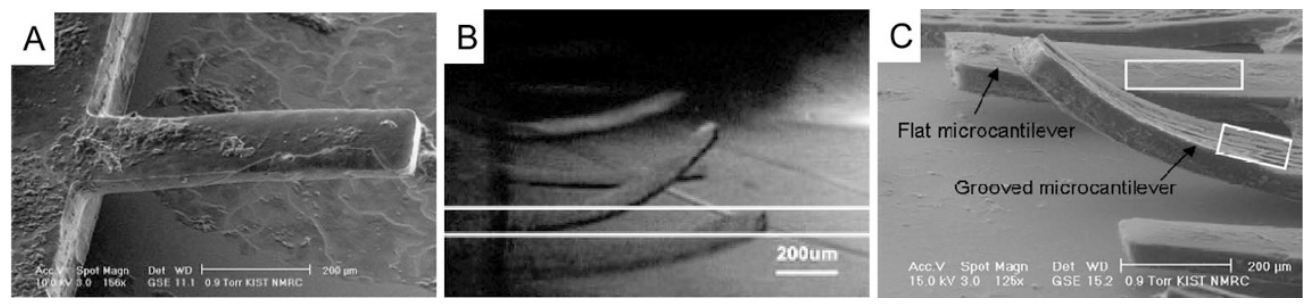

Figure 5. (A). Neonatal rat cardiomyocytes cultured on a PDMS cantilever. Reprinted with permission from Anal Chem (73). Copyright 2005, The American Chemical Society. $(B)$. Vertical bending of PDMS cantilever due to applied strain from cells. Reprinted with permission from Conf Proc IEEE Eng Med Biol Soc (74). Copyright 2000, IEEE. (C). Side-by-side flat and grooved PDMS microcantilevers. The grooved cantilever shows greater deflection than the flat cantilever because more stress is applied along the long-axis of the cantilever. Image reprinted from Park J, et al., J Micromech Microeng 16:1614-1619, Copyright (c) 2006 IOP Publishing Ltd., with permission. 
A

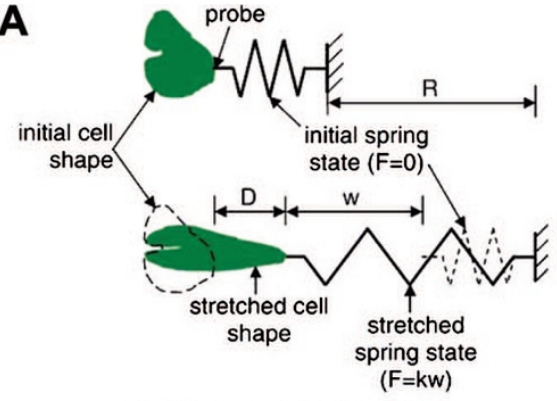

R: movement of the sensor base

D: cell deformation

B

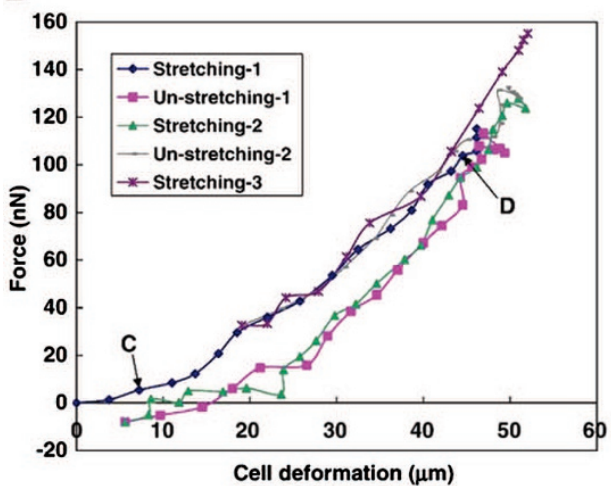

C

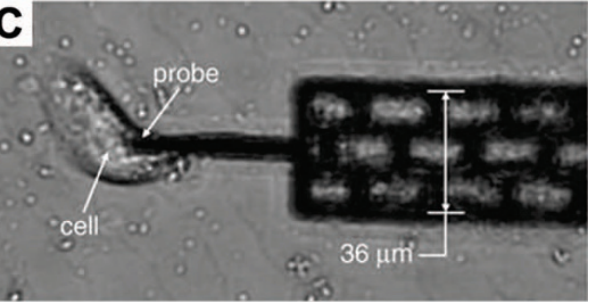

D
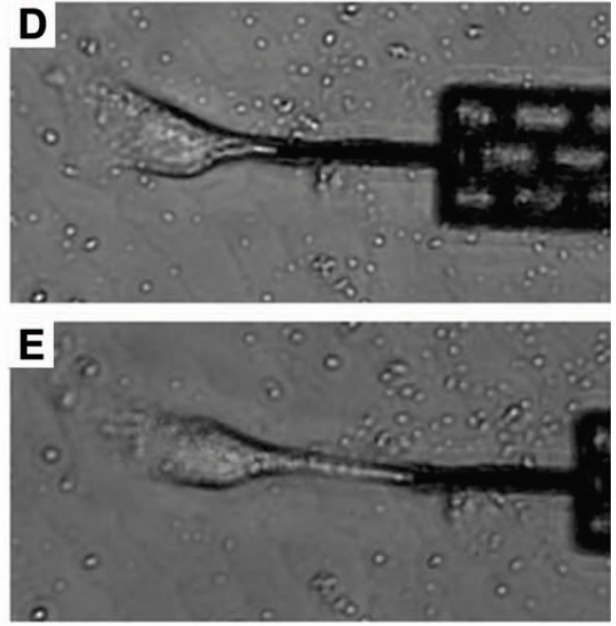

Figure 6. (A). Schematic of cell stiffness measurement with cantilever deflection and cell deformation. The probe is pulled to a distance $R$ by an external actuator, deforming the cell by $D$. The force is measured from the calibrated spring stiffness and deflection, $w$. (B). Force-deflection plot of a cell indicating reversible and repeatable deformation. $(B-D)$. Images of measured cell after probe attachment $(B)$, under small deformation $(C)$ and large deformation $(D)$ corresponding to data in $(A)$. Image reprinted from Yang $S$ and Saif T, Exp Cell Res 305:42-50, Copyright (c) 2005 Elsevier Inc., with permission. inhibitor. The responses suggested a reversible polymerization mechanism maintains cell stiffness over many cycles (78). This technique had the specific advantage of measuring large cell deformations, making it useful for understanding cell response to large strain events or injuries. Such measurements can enable an understanding of the physiologic processes involved in defining and maintaining the structure of cells. The calibrated, single-crystal silicon probes used in this work provided some of the most precise, quantitative data reported from cell mechanics studies.

Sun et al. developed a dual-axis electrostatic actuator system with capacitive displacement sensing for feedback control that was well suited for biomechanical studies of single cells. The system comprised comb-drive electrostatic actuators on a suspended $\mathrm{x}-\mathrm{y}$ stage, allowing a silicon probe to be manipulated in a plane, and capacitive sensors to measure the displacement $(79,80)$. The system was used to measure the extra-cellular membrane stiffness of zona pellucida oocytes (Fig. 7) (79). The stiff probe entered the cell culture media but the combs remained in air. Mechanical models describing the membrane deformation were fit to measured forces and properties of the cell membrane were extracted.

\section{CONCLUSION}

Microsystems technology is promising for various cell mechanics applications. The dimensions, force, and displacement ranges of these devices can be matched to the biological

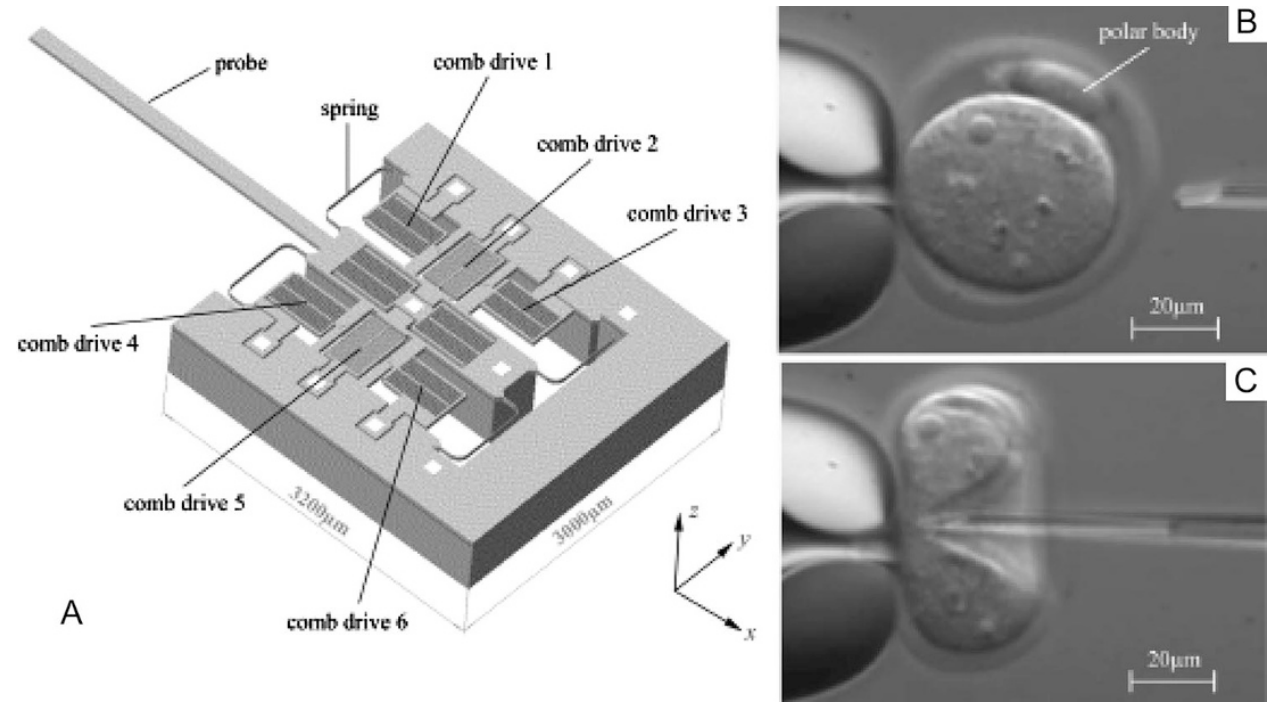

Figure 7. (A). Image of dual-axis actuator and capacitive force sensor for cell manipulation studies. The comb-drives are used to actuate the probe and interdigitated capacitances are used for measuring the force in both axes. $(B, C)$. Images of undeformed $(B)$ and deformed $(C)$ mouse oocyte $\mathrm{ZP}$ with an applied force of $7.21 \mu \mathrm{N}$ and deflection of $42.2 \mu \mathrm{m}$. Image reprinted from Sun Y, et al., IEEE Trans Nanobioscience 2:279-286, Copyright (C) 2003 IEEE, with permission. 
systems under study. For instance, modifications of TFM and mPADs have also been used to study animal locomotion (81). Further, the variety of sensing techniques allows flexible measurement techniques to be tailored for a specific cell type and measurement. Some of the recent progress includes embedding sensors into the force transducers, enabling direct readout of the forces and circumventing elaborate optical setups and image processing (82). This could also lead to higher bandwidth recording for dynamic measurements or integration with patch clamp recordings. Other advances like the development of microactuators in liquid media also have potential applications in controlled application of forces to study cell mechanics (83). New techniques are also being developed that could bridge the gap between IC-based devices and soft-polymer devices. Adding circuitry into soft polymers is an active area of research (84). Incorporation of magnetic particles into mPADs posts has been demonstrated (85). This technique allows for applying forces to the cell, through the micropost, by using magnetic fields.

Advances in fabrication techniques are one way to improve the study of biological phenomena. Another issue that needs to be addressed beyond fabrication is how to study cells, using these techniques, in a manner that is more similar to the in vivo, physiologic state of cells. The described techniques only study cells in a planar or 2D arrangement, but cells grown in $3 \mathrm{D}$ gels that more naturally mimic the in vivo environment exhibit changes in growth and function (86-89). At present, no techniques have been reported to measure traction forces in individual cells in a 3D environment, but extending these techniques to tri-axial stresses and strains will be important. Studying mechanical activity in 3D in vitro environments will lead to greater insight into how cells behave in their natural state, lead to techniques to be applied in vivo, and may ultimately be able to guide the design of in vitro environments for tissue engineering and regenerative medicine.

\section{REFERENCES}

1. Ingber DE 2003 Tensegrity II. How structural networks influence cellular information processing networks. J Cell Sci 116:1397-1408

2. Dike LE, Chen CS, Mrksich M, Tien J, Whitesides GM, Ingber DE 1999 Geometric control of switching between growth, apoptosis, and differentiation during angiogenesis using micropatterned substrates. In Vitro Cell Dev Biol Anim 35:441-448

3. Ingber DE 2003 Tensegrity I. Cell structure and hierarchical systems biology. J Cell Sci 116:1157-1173

4. Paszek MJ, Weaver VM 2004 The tension mounts: mechanics meets morphogenesis and malignancy. J Mammary Gland Biol Neoplasia 9:325-342

5. Oster GF, Murray JD, Harris AK 1983 Mechanical aspects of mesenchymal morphogenesis. J Embryol Exp Morphol 78:83-125

6. Filas BA, Efimov IR, Taber LA 2007 Optical coherence tomography as a tool for measuring morphogenetic deformation of the looping heart. Anat Rec (Hoboken) 290:1057-1068

7. Voronov DA, Alford PW, Xu G, Taber LA 2004 The role of mechanical forces in dextral rotation during cardiac looping in the chick embryo. Dev Biol 272:339-350

8. Itasaki N, Nakamura H, Sumida H, Yasuda M 1991 Actin bundles on the right side in the caudal part of the heart tube play a role in dextro-looping in the embryonic chick heart. Anat Embryol (Berl) 183:29-39

9. Ehler E, Perriard JC 2000 Cardiomyocyte cytoskeleton and myofibrillogenesis in healthy and diseased heart. Heart Fail Rev 5:259-269

10. Granzier H, Wu Y, Siegfried L, LeWinter M 2005 Titin: physiological function and role in cardiomyopathy and failure. Heart Fail Rev 10:211-223

11. LeWinter MM 2005 Functional consequences of sarcomeric protein abnormalities in failing myocardium. Heart Fail Rev 10:249-257

12. Lorenzen-Schmidt I, Stuyvers BD, ter Keurs HE, Date MO, Hoshijima M, Chien KR, McCulloch AD, Omens JH 2005 Young MLP deficient mice show diastolic dysfunction before the onset of dilated cardiomyopathy. J Mol Cell Cardiol 39:241250
13. Makarenko I, Opitz CA, Leake MC, Neagoe C, Kulke M, Gwathmey JK, del Monte F, Hajjar RJ, Linke WA 2004 Passive stiffness changes caused by upregulation of compliant titin isoforms in human dilated cardiomyopathy hearts. Circ Res 95:708716

14. Suresh S, Spatz J, Mills JP, Micoulet A, Dao M, Lim CT, Beil M, Seufferlein T 2005 Connections between single-cell biomechanics and human disease states: gastrointestinal cancer and malaria. Acta Biomater 1:15-30

15. Desmouliere A, Chaponnier C, Gabbiani G 2005 Tissue repair, contraction, and the myofibroblast. Wound Repair Regen 13:7-12

16. Hinz B, Phan SH, Thannickal VJ, Galli A, Bochaton-Piallat ML, Gabbiani G 2007 The myofibroblast: one function, multiple origins. Am J Pathol 170:1807-1816

17. Eckes B, Zweers MC, Zhang ZG, Hallinger R, Mauch C, Aumailley M, Krieg T 2006 Mechanical tension and integrin alpha 2 beta 1 regulate fibroblast functions. J Investig Dermatol Symp Proc 11:66-72

18. Kessler D, Dethlefsen S, Haase I, Plomann M, Hirche F, Krieg T, Eckes B 2001 Fibroblasts in mechanically stressed collagen lattices assume a "synthetic" phenotype. J Biol Chem 276:36575-36585

19. Frisen M, Magi M, Sonnerup L, Viidik A 1969 Rheological analysis of soft collagenous tissue. Part II: experimental evaluations and verifications. J Biomech 2:21-28

20. Kempson GE, Muir H, Pollard C, Tuke M 1973 The tensile properties of the cartilage of human femoral condyles related to the content of collagen and glycosaminoglycans. Biochim Biophys Acta 297:456-472

21. Parodi EN, Kaiser GA, Wolff M, Kovalik AT, Malm JR 1972 Comparative study of the tensile strength of autogenous systemic veins and preserved venous homografts. J Surg Res 12:99-104

22. Brandt PW, Colomo F, Piroddi N, Poggesi C, Tesi C 1998 Force regulation by Ca2+ in skinned single cardiac myocytes of frog. Biophys J 74:1994-2004

23. Brady AJ 1991 Mechanical properties of isolated cardiac myocytes. Physiol Rev 71:413-428

24. Vannier C, Chevassus H, Vassort G 1996 Ca-dependence of isometric force kinetics in single skinned ventricular cardiomyocytes from rats. Cardiovasc Res 32:580-586

25. Sathuluri RR, Yamamura S, Tamiya E 2008 Microsystems technology and biosensing. Adv Biochem Eng Biotechnol 109:285-350

26. Zaouk R, Park BY, Madou MJ 2006 Introduction to microfabrication techniques. Methods Mol Biol 321:5-15

27. Ziaie B, Baldi A, Lei M, Gu Y, Siegel RA 2004 Hard and soft micromachining for BioMEMS: review of techniques and examples of applications in microfluidics and drug delivery. Adv Drug Deliv Rev 56:145-172

28. Norman JJ, Desai TA 2006 Methods for fabrication of nanoscale topography for tissue engineering scaffolds. Ann Biomed Eng 34:89-101

29. Bashir R 2004 BioMEMS: state-of-the-art in detection, opportunities and prospects. Adv Drug Deliv Rev 56:1565-1586

30. Folch A, Toner M 2000 Microengineering of cellular interactions. Annu Rev Biomed Eng 2:227-256

31. Li N, Tourovskaia A, Folch A 2003 Biology on a chip: microfabrication for studying the behavior of cultured cells. Crit Rev Biomed Eng 31:423-488

32. Van Vliet KJ, Bao G, Suresh S 2003 The biomechanics toolbox: experimental approaches for living cells and biomolecules. Acta Materialia 51:5881-5905

33. Whitesides GM, Ostuni E, Takayama S, Jiang X, Ingber DE 2001 Soft lithography in biology and biochemistry. Annu Rev Biomed Eng 3:335-373

34. Harris AK, Wild P, Stopak D 1980 Silicone rubber substrata: a new wrinkle in the study of cell locomotion. Science 208:177-179

35. Galbraith CG, Sheetz MP 1997 A micromachined device provides a new bend on fibroblast traction forces. Proc Natl Acad Sci USA 94:9114-9118

36. Galbraith CG, Yamada KM, Sheetz MP 2002 The relationship between force and focal complex development. J Cell Biol 159:695-705

37. Wang YL, Pelham RJ Jr 1998 Preparation of a flexible, porous polyacrylamide substrate for mechanical studies of cultured cells. Methods Enzymol 298:489-496

38. Munevar S, Wang Y, Dembo M 2001 Traction force microscopy of migrating normal and H-ras transformed 3T3 fibroblasts. Biophys J 80:1744-1757

39. Pelham RJ Jr, Wang Y 1999 High resolution detection of mechanical forces exerted by locomoting fibroblasts on the substrate. Mol Biol Cell 10:935-945

40. Beningo KA, Dembo M, Kaverina I, Small JV, Wang YL 2001 Nascent focal adhesions are responsible for the generation of strong propulsive forces in migrating fibroblasts. J Cell Biol 153:881-888

41. Merkel R, Kirchgessner N, Cesa CM, Hoffmann B 2007 Cell force microscopy on elastic layers of finite thickness. Biophys J 93:3314-3323

42. Lee J 2007 The use of gelatin substrates for traction force microscopy in rapidly moving cells. Methods Cell Biol 83:297-312

43. Lombardi ML, Knecht DA, Dembo M, Lee J 2007 Traction force microscopy in Dictyostelium reveals distinct roles for myosin II motor and actin-crosslinking activity in polarized cell movement. J Cell Sci 120:1624-1634

44. Wang JH, Lin JS 2007 Cell traction force and measurement methods. Biomech Model Mechanobiol 6:361-371

45. Chen J, Li H, SundarRaj N, Wang JH 2007 Alpha-smooth muscle actin expression enhances cell traction force. Cell Motil Cytoskeleton 64:248-257

46. Beningo KA, Hamao K, Dembo M, Wang YL, Hosoya H 2006 Traction forces of fibroblasts are regulated by the Rho-dependent kinase but not by the myosin light chain kinase. Arch Biochem Biophys 456:224-231

47. Rabinovitz I, Gipson IK, Mercurio AM 2001 Traction forces mediated by alpha6beta4 integrin: implications for basement membrane organization and tumor invasion. Mol Biol Cell 12:4030-4043

48. Rabinovitz I, Mercurio AM 1996 The integrin alpha 6 beta 4 and the biology of carcinoma. Biochem Cell Biol 74:811-821 
49. An SS, Pennella CM, Gonnabathula A, Chen J, Wang N, Gaestel M, Hassoun PM, Fredberg JJ, Kayyali US 2005 Hypoxia alters biophysical properties of endothelial cells via p38 MAPK- and Rho kinase-dependent pathways. Am J Physiol Cell Physiol 289:C521-C530

50. Curtze S, Dembo M, Miron M, Jones DB 2004 Dynamic changes in traction forces with DC electric field in osteoblast-like cells. J Cell Sci 117:2721-2729

51. Ghosh K, Pan Z, Guan E, Ge S, Liu Y, Nakamura T, Ren XD, Rafailovich M, Clark RA 2007 Cell adaptation to a physiologically relevant ECM mimic with different viscoelastic properties. Biomaterials 28:671-679

52. Gaudet C, Marganski WA, Kim S, Brown CT, Gunderia V, Dembo M, Wong JY 2003 Influence of type I collagen surface density on fibroblast spreading, motility, and contractility. Biophys J 85:3329-3335

53. Munevar S, Wang YL, Dembo M 2001 Distinct roles of frontal and rear cellsubstrate adhesions in fibroblast migration. Mol Biol Cell 12:3947-3954

54. Balaban NQ, Schwarz US, Riveline D, Goichberg P, Tzur G, Sabanay I, Mahalu D, Safran S, Bershadsky A, Addadi L, Geiger B 2001 Force and focal adhesion assembly: a close relationship studied using elastic micropatterned substrates. Nat Cell Biol 3:466-472

55. Tan JL, Tien J, Pirone DM, Gray DS, Bhadriraju K, Chen CS 2003 Cells lying on a bed of microneedles: an approach to isolate mechanical force. Proc Natl Acad Sci USA 100:1484-1489

56. Sniadecki NJ, Chen CS 2007 Microfabricated silicone elastomeric post arrays for measuring traction forces of adherent cells. Methods Cell Biol 83:313-328

57. Zhao Y, Lim CC, Sawyer DB, Liao R, Zhang X 2005 Cellular force measurements using single-spaced polymeric microstructures: isolating cells from base substrate. J Micromech Microeng 15:1649-1656

58. Lemmon CA, Sniadecki NJ, Ruiz SA, Tan JL, Romer LH, Chen CS 2005 Shear force at the cell-matrix interface: enhanced analysis for microfabricated post array detectors. Mech Chem Biosyst 2:1-16

59. Li B, Xie L, Starr ZC, Yang Z, Lin JS, Wang JH 2007 Development of micropost force sensor array with culture experiments for determination of cell traction forces. Cell Motil Cytoskeleton 64:509-518

60. du Roure O, Saez A, Buguin A, Austin RH, Chavrier P, Silberzan P, Ladoux B 2005 Force mapping in epithelial cell migration. Proc Natl Acad Sci USA 102:2390-2395

61. Saez A, Ghibaudo M, Buguin A, Silberzan P, Ladoux B 2007 Rigidity-driven growth and migration of epithelial cells on microstructured anisotropic substrates. Proc Natl Acad Sci USA 104:8281-8286

62. Ganz A, Lambert M, Saez A, Silberzan P, Buguin A, Mege RM, Ladoux B 2006 Traction forces exerted through N-cadherin contacts. Biol Cell 98:721-730

63. Engler AJ, Sen S, Sweeney HL, Discher DE 2006 Matrix elasticity directs stem cell lineage specification. Cell 126:677-689

64. Zhao Y, Lim CC, Sawyer DB, Liao R, Zhang X 2007 Simultaneous orientation and cellular force measurements in adult cardiac myocytes using three-dimensional polymeric microstructures. Cell Motil Cytoskeleton 64:718-725

65. Tanaka Y, Morishima K, Shimizu T, Kikuchi A, Yamato M, Okano T, Kitamori T 2006 Demonstration of a PDMS-based bio-microactuator using cultured cardiomyocytes to drive polymer micropillars. Lab Chip 6:230-235

66. Zhao Y, Zhang X 2006 Cellular mechanics study in cardiac myocytes using PDMS pillars array. Sens Actuators A Phys 125:398-404

67. Atherton BT, Meyer DM, Simpson DG 1986 Assembly and remodelling of myofibrils and intercalated discs in cultured neonatal rat heart cells. J Cell Sci 86:233-248

68. Motlagh D, Hartman TJ, Desai TA, Russell B 2003 Microfabricated grooves recapitulate neonatal myocyte connexin 43 and $\mathrm{N}$-cadherin expression and localization. J Biomed Mater Res A 67:148-157
69. Lin G, Pister KS, Roos KP 2000 Micromachined polysilicon heart cell force transducer. IEEE ASME J Microelectromech Syst 9:9-17

70. Lin G, Pister KS, Roos KP 1995 Novel microelectromechanical system force transducer to quantify contractile characteristics from isolated cardiac-muscle-cells. J Electrochem Soc 142:L31-L33

71. Pister K, Judy M, Burgett S, Fearing R 1992 Microfabricated hinges. Sens Actuators A Phys 33:249-256

72. Tasche C, Meyhofer E, Brenner B 1999 A force transducer for measuring mechanical properties of single cardiac myocytes. Am J Physiol 277:H2400-H2408

73. Park J, Ryu J, Choi SK, Seo E, Cha JM, Ryu S, Kim J, Kim B, Lee SH 2005 Real-time measurement of the contractile forces of self-organized cardiomyocytes on hybrid biopolymer microcantilevers. Anal Chem 77:6571-6580

74. Kim J, Park J, Ryu SK, Baek J, Park S, Kim HC, Chun K 2006 Realistic computational modeling for hybrid biopolymer microcantilevers. Conf Proc IEEE Eng Med Biol Soc 1:2102-2105

75. Park J, Kim J, Roh D, Park S, Kim B, Chun K 2006 Fabrication of complex 3D polymer structures for cell-polymer hybrid systems. J Micromech Microeng 16:1614-1619

76. Saif MT, Sager CR, Coyer S 2003 Functionalized biomicroelectromechanical systems sensors for force response STUDY at local adhesion sites of single living cells on substrates. Ann Biomed Eng 31:950-961

77. Yang S, Saif MT 2007 Force response and actin remodeling (agglomeration) in fibroblasts due to lateral indentation. Acta Biomater 3:77-87

78. Yang S, Saif T 2005 Reversible and repeatable linear local cell force response under large stretches. Exp Cell Res 305:42-50

79. Sun Y, Wan KT, Roberts KP, Bischof JC, Nelson BJ 2003 Mechanical property characterization of mouse zona pellucida. IEEE Trans Nanobioscience 2:279-286

80. Sun Y, Nelson B 2003 MEMS for cellular force measurements and molecular detection. Int J Inform Acquis 1:23-32

81. Rieu JP, Barentin C, Maeda Y, Sawada Y 2005 Direct mechanical force measurements during the migration of Dictyostelium slugs using flexible substrata. Biophys J 89:3563-3576

82. Park SJ, Goodman MB, Pruitt BL 2007 Analysis of nematode mechanics by piezoresistive displacement clamp. Proc Natl Acad Sci USA 104:17376-17381

83. Sounart TL, Michalske TA, Zavadil KR 2005 Frequency-dependent electrostatic actuation in microfluidic MEMS. IEEE ASME J Microelectromech Syst 14:125-133

84. Guven D, Weiland JD, Maghribi M, Davidson JC, Mahadevappa M, Roizenblatt R, Qiu G, Krulevitz P, Wang X, Labree L, Humayun MS 2006 Implantation of an inactive epiretinal poly(dimethyl siloxane) electrode array in dogs. Exp Eye Res $82: 81-90$

85. Sniadecki NJ, Anguelouch A, Yang MT, Lamb CM, Liu Z, Kirschner SB, Liu Y, Reich DH, Chen CS 2007 Magnetic microposts as an approach to apply forces to living cells. Proc Natl Acad Sci USA 104:14553-14558

86. Bissell MJ, Radisky DC, Rizki A, Weaver VM, Petersen OW 2002 The organizing principle: microenvironmental influences in the normal and malignant breast. Differentiation 70:537-546

87. Bissell MJ, Rizki A, Mian IS 2003 Tissue architecture: the ultimate regulator of breast epithelial function. Curr Opin Cell Biol 15:753-762

88. Gudjonsson T, Ronnov-Jessen L, Villadsen R, Bissell MJ, Petersen OW 2003 To create the correct microenvironment: three-dimensional heterotypic collagen assays for human breast epithelial morphogenesis and neoplasia. Methods 30:247-255

89. Weaver VM, Fischer AH, Peterson OW, Bissell MJ 1996 The importance of the microenvironment in breast cancer progression: recapitulation of mammary tumorigenesis using a unique human mammary epithelial cell model and a threedimensional culture assay. Biochem Cell Biol 74:833-851 